\title{
Interculturalidade nas licenciaturas: ressignificando práticas docentes e saberes do
}

\author{
campo \\ Interculturality in the degrees: re-signifying teaching practices and knowledge of the field \\ Interculturalidad en los grados: resignificando prácticas docentes y saberes del campo
}

Recebido: 10/01/2022 | Revisado: 15/01/2022 | Aceito: 20/01/2022 | Publicado: 22/01/2022

\author{
Renata Moraes de Oliveira \\ ORCID: https://orcid.org/0000-0002-8279-7580 \\ Universidade Federal do Pará, Brasil \\ E-mail: renata.oliveira8013@gmail.com \\ Paulo André Ignacio Pontes \\ ORCID: https://orcid.org/0000-0002-7107-9655 \\ Instituto Federal do Pará, Brasil \\ E-mail: paulo.pontes@ifpa.edu.br \\ Marcos César da Rocha Seruffo \\ ORCID: https://orcid.org/0000-0002-8106-0560 \\ Universidade Federal do Pará, Brasil \\ E-mail: seruffo@ufpa.br
}

\begin{abstract}
Resumo
A Educação do campo e os saberes interculturais são elementos indissociáveis para uma educação transformadora, sob essa premissa a pesquisa pretende problematizar a formação inicial de professores e prover discussões sobre as mudanças necessárias às práticas pedagógicas para o ensino básico do campo. Diante disso, temos como ponto de partida a seguinte questão: Como vem sendo realizada essa interculturalidade nas práticas docentes? Como objetivos específicos, a pesquisa propõe-se a identificar o que vem sendo discutido academicamente nos periódicos CAPES sobre as práticas pedagógicas para educação básica, bem como analisar como a formação inicial sob a ótica intercultural reflete sobre as práticas pedagógicas e assim confrontar as bases norteadoras oficiais e seus caminhos teórico-práticos. A metodologia empregada é de cunho qualitativo e bibliográfico com análise de conteúdo de uma revisão sistemática da literatura (RSL), no site do periódico CAPES, acerca de práticas pedagógicas desenvolvidas na educação básica do campo; seguido por aplicação de questionário semiestruturado a professores do campo. Os resultados apontam que as pesquisas voltadas às práticas ativas no ensino fundamental ainda requerem maiores investigações e que propostas interculturais demonstram melhores resultados quanto ao engajamento, senso de pertencimento e ressignificação de saberes escolares.
\end{abstract}

Palavras-chave: Educação do campo; Ensino básico; Práticas pedagógicas; Interculturalidade.

\begin{abstract}
Rural education and intercultural knowledge are inseparable elements for a transformative education, under this premise, discussions emerge about the necessary changes in pedagogical practices for basic rural education. Therefore, we have as a starting point the following question: How has this interculturality been carried out in teaching practices? as specific objectives, it is proposed to identify what has been academically discussed in CAPES journals about pedagogical practices for basic education; as well as Analyzing how initial training from an intercultural perspective reflects on pedagogical practices and thus confronting the official guiding bases and their theoretical-practical paths. The methodology used is of a qualitative nature; bibliographic with content analysis through a systematic literature review (RSL) in CAPES journals about pedagogical practices developed for rural education in basic education; followed by the application of a semi-structured questionnaire to teachers in the field of basic education. The results show that research aimed at active practices in elementary school still requires further investigations and intercultural proposals demonstrate better results in terms of engagement, sense of belonging and resignification of school knowledge.
\end{abstract}

Keywords: Countryside education; Basic education; Pedagogical practices; Interculturality.

\section{Resumen}

La educación rural y el conocimiento intercultural son elementos inseparables para una educación transformadora, bajo esta premisa surgen discusiones sobre los cambios necesarios en las prácticas pedagógicas para la educación rural básica. Por tanto, tenemos como punto de partida la siguiente pregunta: ¿Cómo se ha llevado a cabo esta interculturalidad en las prácticas docentes? como objetivos específicos, se propone identificar lo que se ha discutido académicamente en las revistas CAPES sobre prácticas pedagógicas para la educación básica; así como Analizar 
cómo la formación inicial desde una perspectiva intercultural reflexiona sobre las prácticas pedagógicas y confrontando así las bases rectoras oficiales y sus trayectorias teórico-prácticas. La metodología utilizada es de carácter cualitativo; bibliográfico con análisis de contenido a través de una revisión sistemática de la literatura (RSL) en revistas CAPES sobre prácticas pedagógicas desarrolladas para la educación rural en educación básica; seguido de la aplicación de un cuestionario semiestructurado a los docentes del ámbito de la educación básica. Los resultados muestran que las investigaciones dirigidas a las prácticas activas en la escuela primaria aún requieren más investigaciones y las propuestas interculturales demuestran mejores resultados en términos de compromiso, sentido de pertenencia y resignificación del conocimiento escolar.

Palabras clave: Educación rural; Educacion basica; Prácticas pedagógicas; Interculturalidad.

\section{Introdução}

As lutas campesinas emergiram dos movimentos sociais do campo em busca de equidade social, qualidade de vida e também no ensino. No que tange à educação, essas lutas têm base nos documentos legais vigentes como: no direito subjetivo promulgado no Art.205. da Constituição que prevê "a educação como direito de todos e dever do Estado" (Brasil, 2016, p.123), dever esse, que não atinge igualmente os diferentes níveis e modalidades de ensino e que merece maior atenção.

Na Lei de Diretrizes e Bases da Educação (LDB 9394/96) em sua finalidade prevista no Art. 22 em "assegurar a formação comum indispensável para o exercício da cidadania e fornecer-lhe meios para progredir no trabalho e em estudos posteriores" (p. 16), mais uma vez é possível questionar a quais trabalhos e estudos e se estes seriam dentro ou fora da sua comunidade. O questionamento faz-se pertinente e seus desdobramentos terão maiores discussões adiante nas habilidades pretendidas nas disciplinas de artes, geografia e história propostas na Base Comum Curricular (BNCC, 2017) que anseia que ao final do ensino básico os educandos percebam e entendam as diversidades culturais.

Nas Diretrizes Operacionais para a Educação Básica nas Escolas do Campo (Brasil, 2002, p. 1) fica ainda mais evidente o olhar sobre as propostas pedagógicas e a necessidade de respeitar as diferenças, em seu Art. $5^{\circ}$ que diz "respeitar as diferenças e o direito à igualdade", que nas diretrizes complementares (Brasil, 2008) reafirma "respeitarão as diferenças entre as populações atendidas quanto à sua atividade econômica, seu estilo de vida, sua cultura e suas tradições” (p. 3).

Os documentos citados reconhecem as possibilidades interculturais de uma educação voltada às singularidades do campo e de diferentes culturas. Entretanto, é importante questionar se somente isso é realmente suficiente para prover mudanças significativas para esses sujeitos.

Diante das necessidade de atender as especificidades educativas do campo e de políticas públicas voltadas a esse segmento que o Programa Nacional de Educação na Reforma Agrária (Pronera) discorre sobre a democratização do conhecimento no campo, integrado ao Ministério do Desenvolvimento Agrário (MDA) para dar apoio a essa produção e acesso à cidadania; o Programa de Apoio à Formação Superior em Licenciatura em Educação do Campo (Procampo) e o Programa Nacional de Educação do Campo (Pronacampo) para uma formação voltada a educadores que atuarão nas escolas rurais, iniciativas que já induz sobre o papel crucial da educação e das práticas diferenciadas necessárias para o processo de ressignificação campesina.

Dessa forma, levantamos a discussão sobre a interculturalidade, não a formulada sob viés do colonizador de ações rasas de visão reducionista de mão de obra barata e desqualificada, mas a pretendida em Walsh (2009) aquela que aguce o fortalecimento das estruturas sociais e a dissolução das categorias binárias primitivo-civilizado; tradicional-moderno; superiorinferior (p.16) e para nosso estudo campo-cidade e os seus desdobramentos pedagógicos, em muitos diferenciados.

Não buscamos com isso dizer que o ensino deva ser monocultural de repetição de atividades da cidade (Fleuri e Costa, 2005) mas aproximá-las de práticas que denotem consciência crítica e que estejam em consonância à realidade local e fortaleça a identidade pessoal e cultural concernentes às proposições dadas pelos documentos norteadores da educação do campo.

É pertinente ainda que os próprios camponeses estejam envolvidos nessa elaboração de um currículo pensado para e pelos sujeitos do campo, que entenda suas necessidades, valorize seus saberes com proposições ancoradas nos novos 
paradigmas educacionais e no saberes locais, abandonando as práticas de outrora do ensino bancário de caráter assistencialista de repetição descontextualizadas que em nada os fortalece nas lutas por valorização e equidade social, e mesmo promove o desenraizamento cultural.

Para Candau (2012) "é necessária uma proposta orientada à construção de sociedades democráticas que articulem igualdade e reconhecimento das diferenças culturais", sobretudo com um viés empoderador que insurge contra a colonialidade do saber, e dê voz às identidades não mais como subalternizados, mas como agentes sociais.

Caldart (2002, p. 36) defende a necessidade de políticas e projetos de formação das educadoras e dos educadores do campo[...] porque sabemos que boa parte deste ideário que estamos construindo é algo novo em nossa própria cultura. De certo, há necessidade de reformulação para uma nova identidade de educador que deve ser aflorada desde os movimentos internos por uma educação do campo, mas pensada para e com o homem do campo.

Para isso, desconstruir a subalternização e invisibilidade do homem do campo trabalhando dentro das comunidades campesinas de forma prática com estratégias ativas e interculturais por meio de debates e reflexões que promova inquietações e reflexões pautados sob as tessituras de Freire (2004) de uma pedagogia de perguntas e de inquietações emancipatórias é de suma valia para que reconheçam seus saberes e que se vejam, não mais como local de atraso e exploração, mas de uma cultura a ser respeitada, ouvida e renascida.

Contudo, sabemos que para que muitos desses paradigmas sejam modificados ainda requer ampla discussão, faz-se relevante desconstruir e reconstruir as bases formadoras, neste sentido buscou-se conhecer o que vem sendo trabalhado academicamente sobre as práticas das salas de aula e se esses saberes se aproximam do contexto campesino e quais caminhos vêm seguindo a educação do campo.

Esta pesquisa é relevante por debater a necessidade de mudanças na base formadora docente com propostas de práticas pedagógicas interculturais e interdisciplinares que preparem esse docente para atuação no campo, assim, lançando luz sobre a necessidade de sua percepção emancipatória para o campo. Para isso, este texto tem como ponto de partida a seguinte questão: Como vem sendo realizada a interculturalidade nas práticas educacionais na educação campesina?

Como objetivos específicos propõe-se a analisar o que vem sendo discutido academicamente nos periódicos CAPES sobre as práticas pedagógicas da educação básica no campo e se as práticas apontadas pelos profissionais atuantes convergem às bases norteadoras do ensino do campo. Assim, é feita uma análise de conteúdo de como a formação inicial sob a ótica intercultural docente da educação básica do campo reflete sobre suas práticas pedagógicas, confrontando as bases norteadoras oficiais e seus caminhos teórico-práticos.

\section{Metodologia}

Para a referida pesquisa utilizou-se de duas técnicas de pesquisa qualitativa: a busca por meio de uma Revisão Sistemática da Literatura (RSL) e aplicação de questionário semiestruturado, apresentados em etapas distintas.

A RSL da pesquisa foi definida com base nas orientações dadas por Bianchini (2005) e envolve três etapas principais: planejamento, condução e publicação dos resultados. Durante a etapa de planejamento, os objetivos da pesquisa são listados e um protocolo de revisão é definido. O protocolo ainda especifica as questões de pesquisa, a estratégia a ser utilizada, os critérios de inclusão e exclusão, as fontes de estudos e a string de busca. Na etapa de condução, são selecionados os estudos primários. Então, são realizadas a seleção e avaliação dos estudos em conformidade com os critérios de inclusão e exclusão estabelecidos no protocolo de avaliação. Na fase de resultados, uma vez selecionados os estudos, os dados são extraídos, sintetizados e utilizados para responder às questões de pesquisa.

É importante ressaltar que todo este processo é interativo e deve-se garantir que o planejamento seja adequado. O protocolo deve ser avaliado e caso sejam encontrados problemas, o pesquisador deve retornar à fase de planejamento e revisar 
o protocolo.O questionário semiestruturado foi direcionado a professores paraenses do campo no ensino básico para conhecer as suas práticas e se elas convergem aos saberes do campo.

\subsection{Questões da pesquisa.}

O foco deste estudo visa responder ao seguinte questionamento: A interculturalidade é percebida nas práticas docentes de professores do campo?

\subsection{Seleção dos estudos}

Para a busca dos estudos na RSL, foi realizado um processo de seleção no qual, entre outros, foram abordados os seguintes aspectos: (i) seleção de fonte para a pesquisa; (ii) termos e definição da string de busca; (iii) definição dos critérios de inclusão e exclusão.

\subsection{String de busca}

Os artigos usados neste estudo foram recrutados a partir do uso de termos de busca que consideraram dois tópicos: educação no campo e práticas pedagógicas. Para a educação no campo foram utilizadas as palavras-chave "educação do campo" e "educação rural", para práticas pedagógicas foram utilizadas as palavras-chave "prática pedagógica" e "práticas pedagógicas". O motivo da escolha dos termos é pela sua recorrência em artigos científicos que tratam deste assunto. Assim, a busca ocorreu através da definição de procura nos campos resumo, título e em todo texto, no site do periódico CAPES.

\subsection{Base de dados}

A pesquisa foi realizada na base de dados eletrônica dos periódicos CAPES (www.periodicos.capes.gov.br) por concentrar um expressivo número de revistas indexadas, além da gratuidade de acesso à base de dados.

\subsection{Critérios de inclusão e exclusão}

O foco deste trabalho é voltado (critérios de inclusão) às pesquisas desenvolvidas na educação básica; análise de práticas/métodos desenvolvidos em sala de aula e que os métodos estejam bem definidos. Foram desconsiderados (critérios de exclusão) trabalhos que fossem desenvolvidos para formação de professore/gestores; não estivessem direcionados ao ensino formal; métodos que não fossem claros e de fácil replicação; discussão sobre currículo; voltados à análise de políticas públicas; desenvolvidos no ensino superior; formação continuada de alunos ou professores; artigos incompletos; ou aqueles que não se referiam aos métodos de ensino para educação do campo.

\subsection{Extração dos dados e síntese}

O processo de seleção da RSL foi dividido em quatro etapas, que foram iniciadas após a conclusão da execução da busca na base de dados e ao todo retornaram 63 artigos. A identificação e seleção dos estudos e suas duas fases estão representadas na Figura 1.

Com intuito de refinar nossas buscas foram aplicados novos filtros delimitando o ano de 2008 a 2020; somente artigos; aqueles revisados por pares; e que excluíssem discussões sobre formação de professores, políticas públicas e currículo preconizando aqueles que evidenciassem práticas desenvolvidas em sala de educação básica, resultando em 39 artigos, conforme Figura 1. 
Figura 1: Etapas da RSL

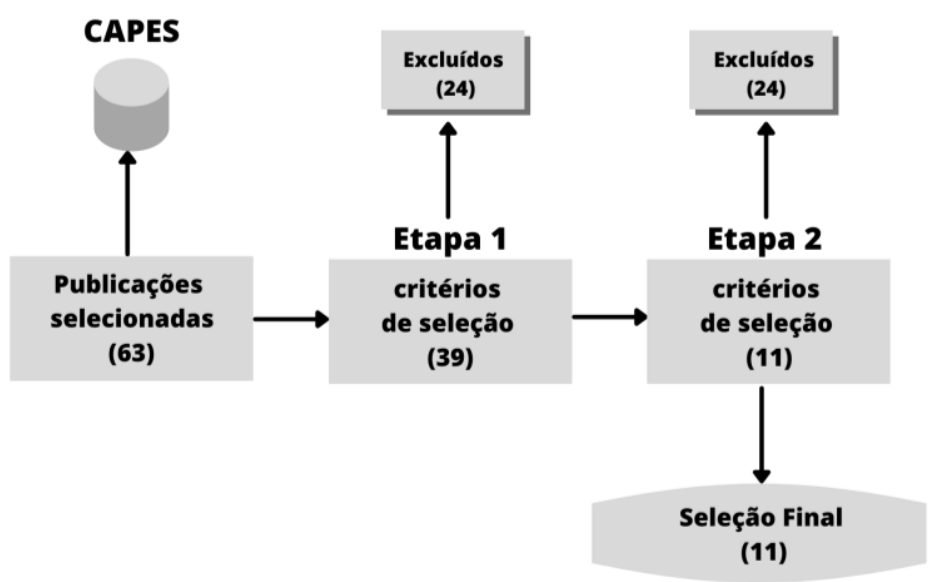

Fonte: Elaborada pelos autores.

Então, foram lidos os resumos e palavras-chaves e a partir das observações, aplicados critérios de inclusão e exclusão do foco da pesquisa, o resultado foi a seleção de 11 artigos, que são apresentados na Quadro 1.

Quadro 1: Descrição dos artigos resultantes da RSL.

\begin{tabular}{|c|c|c|c|c|c|}
\hline $\mathbf{N}^{\circ}$ & AUTORES & DOI & SÉRIES & ESTADO & METODOLOGIA \\
\hline 1 & $\begin{array}{l}\text { ZANLORENZI, M. A.; } \\
\text { OLIVEIRA, A. M. }\end{array}$ & $\begin{array}{c}\text { DOI: /10.23925/1983- } \\
\text { 3156.2017v19i3p209-229 }\end{array}$ & Ensino Médio & Paraná & Etnomatemática \\
\hline 2 & $\begin{array}{l}\text { SANTOS, L. R.; } \\
\text { CHAGAS, P. C. de M. }\end{array}$ & $\begin{array}{c}\text { https://doi.org/10.15628/holos. } \\
2011.643\end{array}$ & $\begin{array}{l}\text { EJA/Ensino } \\
\text { Médio }\end{array}$ & $\begin{array}{l}\text { Rio Grande } \\
\text { do Norte }\end{array}$ & $\begin{array}{l}\text { Aulas orais, leitura de } \\
\text { textos e videoaulas }\end{array}$ \\
\hline 3 & $\begin{array}{l}\text { SILVA, C; } \\
\text { ANDRADE, K. S; } \\
\text { MOREIRA, F. }\end{array}$ & $\begin{array}{c}\text { https://doi.org/10.4025/actascil } \\
\text { angcult.v37i4.25050 }\end{array}$ & $\begin{array}{c}\text { Ensino } \\
\text { Fundamental }\end{array}$ & Tocantins & Caderno da Realidade \\
\hline 4 & PIRES, L. S. & $\begin{array}{c}\text { https://doi.org/10.37084/REM } \\
\text { ATEC.1980- } \\
\text { 3141.2018.n29.p\%p.id152 }\end{array}$ & Ensino Médio & Pará & Modelagem Matemática \\
\hline 5 & $\begin{array}{l}\text { ARAUJO, P.C.A; } \\
\text { NEVES, G.F. }\end{array}$ & $\begin{array}{c}\text { https://doi.org/10.15628/holos. } \\
2017.5769\end{array}$ & Ensino Médio & Paraíba & $\begin{array}{c}\text { Os cordéis como artefato } \\
\text { cultural }\end{array}$ \\
\hline 6 & JESUS, J. N. & $\begin{array}{c}\text { https://doi.org/10.47946/rnera. } \\
\text { v0i18.1334 }\end{array}$ & Ensino Médio & Goiás & $\begin{array}{c}\text { Experimentações/Plano de } \\
\text { Estudo }\end{array}$ \\
\hline 7 & MELO, A. D; S, S C. & $\begin{array}{c}\text { https://doi.org/10.15628/holos. } \\
2013.1375\end{array}$ & $\begin{array}{c}\text { Ensino } \\
\text { Fundamental }\end{array}$ & $\begin{array}{l}\text { Rio Grande } \\
\text { do Norte }\end{array}$ & Livro didático \\
\hline 8 & ALVES, C. G.R. et al. & $\begin{array}{c}\text { https://doi.org/10.22169/revint. } \\
\text { v12i26.1128 }\end{array}$ & Ensino Médio & Roraima & Contos populares \\
\hline 9 & $\begin{array}{l}\text { SOUSA, A. P. F.; et. } \\
\text { al. }\end{array}$ & $\begin{array}{c}\text { https://doi.org/10.20873/uft.25 } \\
\text { 25-4863.2016v1n2p402 }\end{array}$ & Ensino Médio & $\begin{array}{l}\text { Espírito } \\
\text { Santo }\end{array}$ & $\begin{array}{l}\text { Alternância pedagógica e } \\
\text { Temas geradores }\end{array}$ \\
\hline 10 & $\begin{array}{l}\text { SANTOS, G.S; } \\
\text { MOURA, A.C.O. S. }\end{array}$ & $\begin{array}{c}\text { https://doi.org/10.20873/uft.25 } \\
\text { 25-4863.2016v1n2p402 }\end{array}$ & $\begin{array}{l}\text { Ensino } \\
\text { Fundamental e } \\
\text { Médio }\end{array}$ & $\begin{array}{l}\text { Rio Grande } \\
\text { do Sul }\end{array}$ & $\begin{array}{l}\text { Softwares educacionais e } \\
\text { aplicativos em dispositivos } \\
\text { móveis/Modelagem } \\
\text { matemática }\end{array}$ \\
\hline 11 & $\begin{array}{l}\text { CHAGAS, R.R; } \\
\text { PASUSH, J. }\end{array}$ & $\begin{array}{c}\text { https://doi.org/: } \\
\text { 10.30681/2236-3165 }\end{array}$ & $\begin{array}{c}\text { Ensino } \\
\text { Fundamental }\end{array}$ & Mato Grosso & $\begin{array}{c}\text { Roda de leitura/Leitura } \\
\text { deleite }\end{array}$ \\
\hline
\end{tabular}




\subsection{Questionário}

Após os desdobramentos da RSL em que foi possível encontrar trabalhos que versavam sobre práticas com nuances interculturais e interdisciplinares, buscou-se conhecer as práticas pedagógicas na região Norte, para isso foi aplicado um questionário semiestruturado com 15 perguntas sobre a formação inicial; os saberes os quais tiveram contato na graduação; a percepção sobre metodologias ativas e interculturalidade e suas principais dificuldades em promover desdobramentos interculturais dentro da sua formação. Com isso, traçou-se o perfil docente e como sua formação contribui na prática de ensino e se suas práticas convergem nas propostas dos documentos norteadores para a educação do campo. A partir disso foi possível discutir os enlaces do que se propõe as práticas usadas no país e no estado do Pará.

Com o intuito de conhecer as possíveis dificuldades dos docentes paraenses do ensino básico em articular os saberes tradicionais a conteúdos escolares, buscou-se conhecer as possíveis fragilidades educacionais em sua formação inicial e se a ausência de saberes interculturais implica de alguma forma na prática.

Para isso, foi realizada a aplicação de questionário semiestruturado via Google Forms e uso do Whatsapp para socialização em grupos de educação do campo, uma vez que a pesquisa teve seus desdobramentos realizados durante o contexto da pandemia de COVID-19, impossibilitando as entrevistas presenciais. O questionário continha 15 perguntas, das quais analisamos os itens referentes à formação docente intimamente relacionados à educação do campo e as práticas ativas. Visamos, também, conhecer as dificuldades docentes para indução por esse viés intercultural.

Nas perguntas iniciais de 1 a 7, as informações pretendiam traçar o perfil pessoal docente. A pesquisa foi respondida entre os dias 07/06/2021 a 20/08/2021 por 70 professores de educação básica e técnica de 32 municípios paraenses, com idade entre 25 e 53 anos. Desses, $71 \%$ de professores atuantes em nível fundamental, 14,5\% em nível infantil ou técnico com formação nas diversas disciplinas curriculares, e ano de formação compreendido de 1999 a 2020 como observado na Quadro 2.

Vale ressaltar que o maior número de respondentes saiu das universidades nos últimos 14 anos, período em que já se previa institucionalmente a Educação do Campo na LDB 9394/96, e nas Diretrizes Operacionais para a Educação Básica nas Escolas do Campo (Brasil, 2002) ou pelo menos se esperava que tivessem chegado também às universidades essas discussões.

Quadro 2: Perfil pessoal docente.

\begin{tabular}{|l|l|}
\hline Idade & Entre 25 e 53 \\
\hline Nível de atuação & Infantil, Fundamental e Médio \\
\hline Curso & $\begin{array}{l}\text { Pedagogia, Letras, Geografia, História, Matemática, } \\
\text { Ciências Naturais, Educação Física, Artes, Espanhol, } \\
\text { Educação do Campo e Agronomia. }\end{array}$ \\
\hline Ano de formação & De 1999 a 2020 \\
\hline
\end{tabular}

Fonte: Autores.

\section{Resultados e Discussão}

Para melhor compreensão apresentaremos os resultados das pesquisas separadamente para posterior enlace entre eles.

\subsection{Resultados e discussão da RSL}

Foram analisados 11 artigos e seus desdobramentos com intuito de refletir sobre as práticas e proximidades da proposta de educação do campo. Em Zanlorenzi e Oliveira (2017), a pesquisa suscitou sobre um projeto de construção 
curricular diferenciado que considerasse as dificuldades e desafios apresentados na própria localidade, com um viés intercultural, como as lutas por território entre outras dificuldades associadas aos conteúdos matemáticos, contudo os próprios autores tecem discrepância entre o que os professores objetivavam e suas práticas reais de aplicação, mas consideram que há dialogicidade entre os saberes tradicionais e escolares do ensino médio, observamos que a mudança curricular pautada nos saberes locais já é realidade, mas que os professores não tiveram uma preparação prévia, o que desencadeou as dificuldades, não podemos desatrelar o currículo daquele que o colocará em prática.

A pesquisa de Silva et al. (2015) observou a retextualização de um caderno de realidade de um aluno do $9^{\circ}$ ano da EFA de Tocantins, seu foco de pesquisa são as transformações de gêneros escritos, a transposição do conteúdo de um texto para outro, bem como a mudança de gênero, que revela que diante de práticas diferenciadas, porém descontextualizadas não agregam mudanças significativas às práticas de escritas dos educandos, sem relação a vivenciar o aprendido torna-se irrelevante.

Pires (2018) associa a prática de criação bovina e produção de leite à modelagem matemática para o ensino de diversos conteúdos do ensino médio, com condições que instigassem seus educandos a reconhecer, no seu cotidiano, a utilização da matemática voltada à realidade do campo. Para o autor: "eles sentiram-se motivados em produzir questões inerentes à função do $1^{\circ}$ grau" [...] "Pensar o ensino reflexivo para as escolas do campo é fazer um exercício de desconstrução e quebra de paradigmas de um modelo linear e ante reflexivo que não valoriza o contexto e os saberes prévios dos educandos". Dessa forma, descreve o "melhoramento" no ensino-aprendizagem, de posse de algo palpável.

Araújo e Neves (2017) propõem o processo de valorização da memória social e história da localidade por meio da leitura e produção de cordéis como construção e aproximação à realidade política e social de alunos do ensino médio, eles sugerem "trabalhar com metodologias participativas, ações emancipatórias e dialógicas, com a memória social do campo como partícipe da formação dos sujeitos que nele habitam" e propõem que estas metodologias emanam reflexão crítica sobre o meio o qual esse aluno está inserido.

Jesus (2011) traz a reflexão em torno da pedagogia da alternância desenvolvida em sistema de internato em uma Escolas Família Agrícola (EFAs) e regressam a sua comunidade. Neste trabalho foram observados os Plano de Estudos que seriam o levantamento de dados concretos e vivenciados pelos educandos, "O Projeto tem como foco o melhoramento técnico da propriedade", para o autor, a alternância ajuda o aluno a conhecer e valorizar o seu modo de vida, a cultura local e despertar a consciência crítica, mas tecem observações quanto aos profissionais "precisam melhorar a formação dos professores [...] ]encontram muitas dificuldades na prática do ensino da Pedagogia da Alternância e ao mesmo tempo fortalecer a educação profissional de técnico em agropecuária"(p. 14), percebemos que a proposta tem proximidade ao campo, mas é pensada nas secretarias e desconsideram a necessidade de uma formação direcionada a interculturalidade recaindo sobre o professor a busca por adaptar-se ou o descrédito da proposta.

Mello e Souza (2013) trazem uma investigação referenciada pela perspectiva da análise de conteúdo do material didático direcionado à Escola Ativa que é um programa que busca melhorar a qualidade do desempenho escolar em classes multisseriadas das escolas do campo. Os Cadernos de Ensino-Aprendizagem possuem Atividades Básicas (A), Atividades Práticas (B) e Atividades de Aplicação e Compromisso (C). Foi observado que os livros são bastante ilustrados e auto formativos, contudo, ressalta que de modo geral a forma como o homem do campo é apresentado se mostra "de modo estereotipado" e os cadernos de português não estão relacionados ao contexto de vida das crianças do meio rural. Dessa forma, os autores sugerem a reformulação dos materiais para melhor atender ao povo do campo, o que evidencia a necessidade de mudanças conceituais sobre o campo e seus modos de vida, trabalho e importância social.

Alves et al. (2017) em sua pesquisa com estudantes do Curso Técnico em Agropecuária integrado ao Ensino Médio do Instituto Federal de Roraima se propõem a analisar as contribuições da oralidade para educação do campo. "Ao recontar uma 
história, estória ou conto popular, é dada ao aluno a possibilidade de confrontar valores de temporalidades" ainda segundo os autores a oralidade é uma ferramenta que desperta o interesse sobre a realidade brasileira, contribuindo para a compreensão de conteúdos de história, geografia e sociologia, literatura etc. O uso da oralidade promove o compartilhamento de saberes na escola e para além do espaço escolar, mas enfatiza o papel fundante do professor nesse processo, aos professores recai o papel de associar interdisciplinarmente as vivências das proposições pedagógicas para que aconteça um ensino significativo.

A pesquisa de Sousa et al. (2016) foi desenvolvida sob os fazeres pedagógicos de monitores do Ensino Médio/Técnico Profissionalizante em uma EFA do Espírito Santo, sob os Temas Geradores e seus princípios. Os mesmos apontaram que as diferenças regionais exigem uma adequação do profissional ao ambiente e à cultura escolar histórica, para que as práticas se apropriem da realidade e sirvam de base aos novos saberes, demonstraram ainda certa preocupação com os princípios pedagógicos e metodológicos da alternância e sua aplicabilidade pelos profissionais envolvidos.

A investigação apresentada no artigo de Santos e Moura (2020) versa sobre o ensino de Ciências, de maneira contextualizada, e mostrou que o uso de softwares educacionais e modelagem matemática promovem a ação do estudante no processo de aprender; relação entre saberes populares e conhecimento científico com mais autonomia em seus raciocínios e estimulam sua criatividade oferecendo informações e curiosidades sobre o assunto. A investigação também ressalta que as práticas pedagógicas no ensino de ciências vêm diversificando-se por aqueles que estão se formando recentemente e demonstram que algumas universidades já se preocupam em abordagem intercultural em suas proposições pedagógicas.

Chagas e Pasuch (2016) pautam suas observações sob uma professora da turma multisseriada do ensino fundamental em Nova Canaã do Norte/MT e sobre suas práticas de leitura deleite e a escrita desenvolvidas numa linguagem real, natural, significativa e vivenciada. Ressaltam que "ainda existe uma distância entre o que está garantido na lei e a realidade das escolas", mas que o processo de aprendizado muito está relacionado pelo educando na percepção da existência de regras, na organização fomentadora das salas de aula, em práticas instigantes e na elaboração prévia de sequências didáticas, por nós compreendida como interligar os conteúdos trabalhados de forma coesa e com elementos do cotidiano infantil campesino.

Diante dos resultados obtidos na RSL, evidencia-se que dos 11 artigos encontrados, oito são concernentes às práticas de cunho ativo com proximidade intercultural e três de práticas sob viés tradicionais de ensino, sem qualquer proximidade com a realidade local, desenvolvidos em diferentes regiões do país.

É importante frisar que observamos que na região norte do Brasil, encontrou-se apenas um artigo com prática ativa e coerente ao ensino do campo. Contudo, este quantitativo é pequeno, se considerado o número de escolas do campo do estado no total de 7.050 estabelecimentos rurais (INEP, 2018), fato que chama atenção à necessidade de reformular as ações desta natureza para a região.

Sobre as práticas ativas e interculturais, são apontadas nos artigos de despertar o interesse, promovem a dialogicidade e colocam os educandos como agentes que articulam as realidades locais, são descritas também mais suscetíveis à participação dos educandos.

$\mathrm{Na}$ busca por dialogar com os saberes escolares aos tradicionais, para um atendimento mais adequado às populações campesinas dentro de seus espaços, é imprescindível a articulação do currículo ao trabalho, que por sua vez se relaciona diretamente às características da comunidade atendida, de seus saberes, costumes e cultura. Mas os docentes foram preparados para tais tessituras interculturais?

Diante dos artigos observados, as queixas mais recorrentes são as direcionadas às práticas docentes, em como os professores não conseguem realizar a interculturalidade nas diferentes áreas, ainda que já tenha sido modificado o currículo, o professor é a peça-chave dessa reformulação, é evidente que preparar esse docente também é dever do estado e também está previsto nos documentos norteadores, mas ainda não chegou ao campo dentro das regiões de atendimento rural. 


\subsection{Resultados e discussão do questionário}

A partir da aplicação do questionário, apresentamos os seguintes dados na Quadro 3, com as perguntas seguidas dos percentuais obtidos em cada uma das respostas classificadas em SIM, PARCIAL e NÃO, de seus respectivos percentuais apontados no questionário semiestruturado por professores da educação básica do campo paraense.

Quadro 3: Perguntas e Respostas ao questionário semiestruturado.

\begin{tabular}{|l|l|l|l|l|}
\hline \multicolumn{1}{|c|}{$\mathbf{N}^{\mathbf{0}}$} & \multicolumn{1}{|c|}{ PERGUNTAS } & SIM & PARCIAL & NÃO \\
\hline 1 & $\begin{array}{l}\text { Durante a graduação você teve acesso a } \\
\text { metodologias ativas ou diferenciadas para o } \\
\text { ensino? }\end{array}$ & $47,1 \%$ & $30 \%$ & $22,9 \%$ \\
\hline 2 & $\begin{array}{l}\text { Na graduação recebeu alguma instrução } \\
\text { sobre o ensino do campo? }\end{array}$ & $32,9 \%$ & $21,4 \%$ & $45,7 \%$ \\
\hline 3 & $\begin{array}{l}\text { Nas instituições de atuação receberam } \\
\text { alguma formação para esse fim? }\end{array}$ & $37,7 \%$ & $\mathrm{X}$ & $62,3 \%$ \\
\hline 5 & $\begin{array}{l}\text { A instituição de atuação estimula o uso de } \\
\text { práticas metodológicas diferenciadas? }\end{array}$ & $71 \%$ & $\mathrm{X}$ & $29 \%$ \\
\hline 5 & Você faz uso de práticas ativas? & $81,2 \%$ & $\mathrm{X}$ & $18,8 \%$ \\
\hline
\end{tabular}

Fonte: Autores.

Observa-se que aqueles que tiveram contato, ainda que parcialmente, retrataram um quantitativo bem significativo, o que demonstra que a preocupação em apresentar aos futuros docentes a relevância de apresentar os conteúdos de forma dinâmica e engajadora já é discutida nas academias. As demais questões suscitaram em busca de compreender as possíveis problemáticas da falta de contato com a abordagem intercultural e tudo o que isso engloba.

Conforme a pergunta 2, 45,7\% não receberam qualquer informação sobre as singularidades para ensino do campo, importante salientar em Costa e Batista (2021, p. 5) que "A Educação do Campo tem como intencionalidade a formação humana, tendo como finalidade a autonomia e a libertação", mas para que isso ocorra é fundamental que os profissionais sejam preparados para aguçar nos seus alunos essa educação libertadora, e que o alunos sintam-se atendidos pela proposta educativa, cabe às universidades essa iniciação.

E quando isso não acontece? "Verifica-se, assim, que os povos do campo continuam à mercê de uma política excludente e seletiva, que não garante a todos o direito de aprender" (Senra; Vilela, 2020), isto é, ao negar aos profissionais que atenderão a população do campo o conhecimento basilar de seus saberes, identidade e cultura é reafirmada a exclusão como um ato irresponsável, considerando que um quinto da população do país encontra-se na zona rural, somando 32 milhões de pessoas (INEP, 2010). Isto significa negar ensino de qualidade e ferir com o direito dos profissionais da educação.

Se compararmos os dados das questões 1 e 2, em que o número de graduados que não teve acesso às práticas ativas se mostra menor em comparação àqueles que não receberam informações sobre educação do campo, somente $22,9 \%$ faz-nos refletir sobre a invisibilidade das lutas campesinas em se apresentar novas metodologias seja menos relevante do que ensinar sobre as diversas culturas e suas singularidades, como sugeridos em Costa e Batista (2021). É fundamental que o currículo da escola do campo contribua para a formação de uma memória histórica das lutas, da resistência, da identidade, dos processos produtivos, do trabalho no campo; todas essas temáticas trabalhadas de forma interdisciplinar, apoiada na pesquisa como princípio educativo (Costa \& Batista, 2021, 9).

Diante da possibilidade de que professores não tivessem recebido em sua formação inicial informações referentes à educação do campo, buscou-se saber se nas instituições de atuação receberam alguma formação para esse fim. As respostas 
estão na pergunta 3 da tabela 3. Nesta, entende-se que é solicitado a $62,3 \%$ dos docentes que apliquem práticas mais concernentes à vivência local, sem maiores explicações de como viabilizar o processo, recaindo sob o docente a inquietação e responsabilidade de adequar-se, o que nos inquieta a futuras pesquisas em o que poder público tem em suas propostas de políticas públicas que venham a mudar essa situação, uma vez que é dever do Estado a formação continuada prevista na LDB.

Quando indagados como seriam essas formações descreveram que seria de forma extraoficial, com a criação de sequências didáticas ou mesmo que os próprios professores buscassem produzir o material conforme considerasse pertinente à disciplina, sem grande explicação de quais práticas e necessidades de suas comunidades ou ainda uma cartografia mais adequada, uma vez que os professores não são oriundos das comunidades que atuam.

Ainda na Tabela 3, observando a pergunta número 4, trazemos o questionamento se a instituição estimulava o uso de práticas metodológicas diferenciadas. O que observamos é que a cobrança/estímulo de práticas diferenciadas das tradicionais são estimuladas nas instituições apesar de não oferecerem formação adequada, espera-se que o professor as utilize.

Quanto ao questionamento se o docente fazia uso de práticas ativas, de acordo com os dados da pergunta 5 , na tabela 3, percebemos que $81,29 \%$ dos docentes utilizam metodologias ativas em suas aulas, enquanto que $18,2 \%$ não fazem uso. É importante apresentar conjuntamente à análise dessa questão a seguinte que se refere às diversas práticas pedagógicas e a necessidade da interculturalidade no processo de formação do profissional da educação. Observa-se no Gráfico 1 os resultados sobre as práticas mais utilizadas pelos docentes.

Gráfico 1: Práticas docentes.

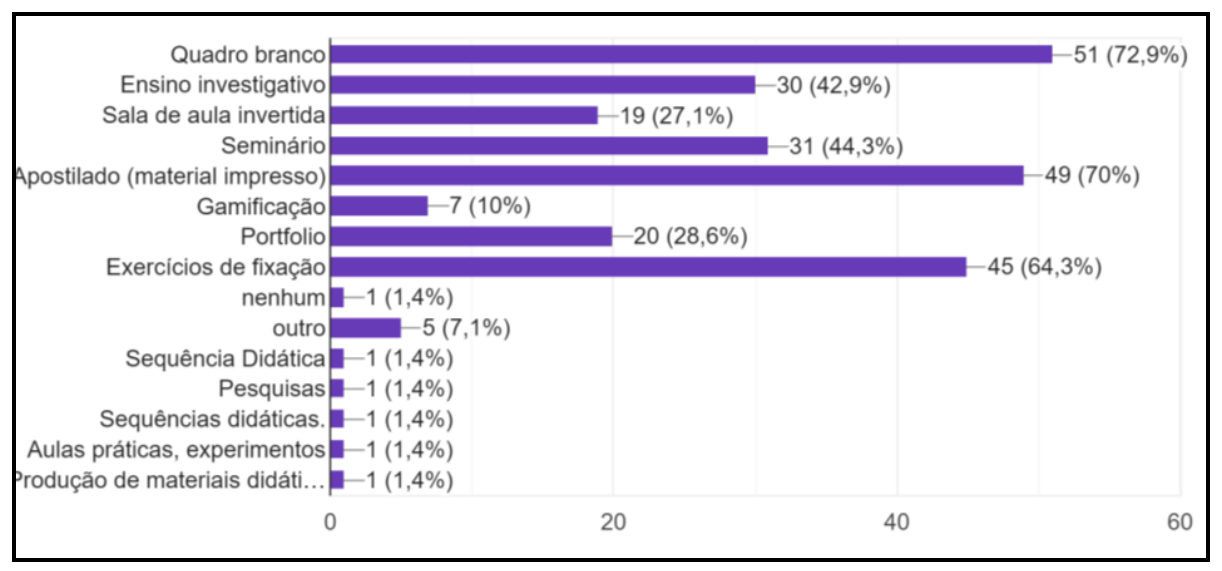

Fonte: Autores.

As análises sugerem que as práticas ativas são pouco utilizadas nas aulas de educação do campo como apontam os dados, ainda que a maioria tenha assinalado que na graduação tiveram acesso e utilizam dessas práticas a partir das respostas observamos que realmente não as utilizam. O que nos propõe que "as mudanças concretas" somente acontecerão se postas em prática (Nóvoa, 2013, p. 201).

Outro item abordado na pesquisa foram as possíveis dificuldades apontadas pelos docentes referentes às práticas ativas, conforme Gráfico 2. 
Gráfico 2: Pergunta - Quais as dificuldades de utilização de práticas ativas nas aulas de educação do campo?

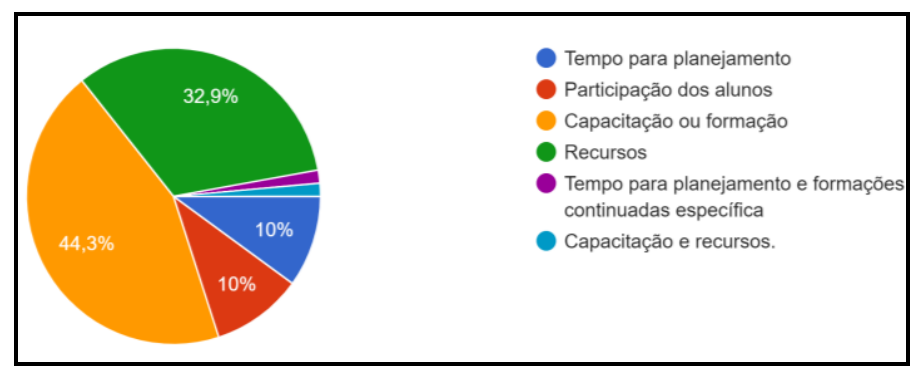

Fonte: Autores.

A falta de capacitação e de recursos foi apontada como fator principal da ausência de aulas mais práticas e ativas, ambas podem ser compreendidas como ausência de políticas públicas que atendam às demandas necessárias para aulas mais dinâmicas e que acabam por recair aos bolsos dos docentes, um patrocínio da mão do próprio trabalhador para aquele que deseja diversificar as aulas, e a desobediência ao $\S 1^{\circ}$ do Art. 62 da LDB define que "a União, o Distrito Federal, os Estados e os Municípios, em regime de colaboração, deverão promover a formação inicial, a continuada e a capacitação dos profissionais de magistério"(Brasil, 2002), dados convergentes ao censo do INEP (2018) que aponta que "Em relação à infraestrutura, ao avaliar a disponibilidade de biblioteca ou sala de leitura nas escolas, um recurso pedagógico essencial para o aprendizado dos alunos, percebe-se que esse recurso é menos encontrado nas Regiões Norte e Nordeste do País” (INEP, 2018, p. 49).

\section{Considerações Finais}

A pesquisa evidencia o quanto é escasso o material voltado ao relato de práticas de sala na educação básica e que os poucos trabalhos encontrados apresentam viés de práticas ativas e interculturais ainda suscintos de práticas realmente voltadas à realidade do campo e com apropriação desses conceitos consolidados nas práticas docente, comumente apontam docentes cheios de dúvidas e apreensões, mas ainda em sua maioria requer uma revisão mais assertiva e delimitada dessa iniciativa, pois a educação do campo não pode ser negligenciada com propostas que não fomentam o senso de pertencimento, territorialidade e desenvolva expertises emancipatórias.

As aulas que abordaram conceitos do campo aconteciam nas EFAS ou em Institutos Federais que têm mais recursos para aulas práticas, como observação de criação de gado e produção de leite dentro do próprio campus, estas instituições possibilitam também experienciar projetos de releitura e escrita em bibliotecas, pois têm disponíveis recursos didáticos e materiais pedagógicos, diferentes das escolas municipais e estaduais que atendem o estado do Pará em que os professores respondentes se deparam com a falta de materiais básicos para aulas mais diferenciadas como cartolinas e mesmo papel para impressão, isto salienta o quanto a estrutura também interfere na construção de aulas mais dinâmicas no processo de ensinoaprendizagem.

Em relação ao currículo, para que as aulas não fiquem descontextualizadas da prática e nem meras repetidoras de materiais da cidade, é fundamental que as instituições promovam formações pedagógicas com os docentes, a fim de aproximar as práticas do que se espera daquele currículo e de possíveis adaptações que insurgem no caminho, assim como também é necessário pensar em fazeres que agucem a curiosidade do educando e caso não dominem essa expertise, busquem por soluções para democratizar o ensino tornando-o significativo.

Informalmente, a dificuldade de formação nas próprias comunidades do campo foi suscitada, o que merece nossas futuras pesquisas em saber se aplicar formações dentro das comunidades culminará em maiores recorrências de práticas ativas também em sala de aula, e se isto contribuirá de alguma forma para mudanças concretas das práticas pedagógicas.

Os objetivos traçados nesta pesquisa, em refletir sobre as práticas docentes e seus enlaces com a educação do campo, apontam que as dificuldades emergem das lacunas e das fragilidades de conhecimento propostos desde a graduação, momento 
no qual o discente está em formação inicial e se apresenta aberto ao que lhes for proposto. O que emana mudanças urgentes no currículo das licenciaturas das diferentes áreas do conhecimento, tanto para exploração democrática e significativa sobre práticas ativas como para inserção de debates interculturais, contextualização histórica do campo e ainda do fomento de políticas públicas que deem suporte aos professores do campo, com materiais e formações que possibilitem, a quem não teve acesso na graduação, ampliar seus sabres.

Negar o saber sobre práticas mais condizentes ao homem do campo é negar as premissas dos documentos que regem a educação do campo, fere com os direitos subjetivos desses sujeitos e promove o desenraizamento do sujeito. A escola precisa ser percebida como símbolo de resistência e de pertencimento, essas mudanças precisam emergir da base que forma esses profissionais para ampliarmos os debates e as formações e as mudanças comecem a refletir em práticas mais engajadoras e participativas no chão da sala de aula também do campo.

Diante da ausência de resultados voltados às séries iniciais, sugerem-se futuras pesquisas para saber se diante do viés interdisciplinar da formação do pedagogo, esta daria subsídios a práticas pedagógicas interculturais. Estudos dessa natureza mostram-se pertinentes para discussão e desdobramentos didáticos em diferentes níveis e modalidades sob a interculturalidade.

\section{Referências}

Gonçalves, R. A. C., Lopes, S. L., \& Mendoza, H. J. G. (2017). Educação do campo e oralidade: contribuições dos contos populares nas escolas do campo. Revista Intersaberes, 12(26). https://doi.org/10.22169/revint.v12i26.1128

Araújo, P. C. de A., \& Neves, G. F. das. (2017). No tear da memória, travessias de história da luta do campo no cordel: educar a juventude em direitos humanos. Holos, 3, 176. https://doi.org/10.15628/holos.2017.5769

Biolchini, J., Mian, P. G., N, A. C. C., and Travassos, G. H. (2005). Systematic review in software engineering. Technical report, RT-ES 679/05 System Engineering and Computer Science COOPEScienceScience COOPE/UFRJ

Brasil. (1988). Constituição da República Federativa do Brasil (1988). Brasília, DF: Senado Federal. http://www.planalto.gov.br/ccivil_03/constituicao/constituicao.htm.

Lei nº 9.394, de 20/12/1996, Lei no 9394 (1996, 23 de dezembro) (Brasil). Diário Oficial da União. https://legis.senado.leg.br/norma/551270.

Brasil. (2017). Base Nacional Comum Curricular. http://basenacionalcomum.mec.gov.br/implementacao/praticas/caderno-de praticas/aprofundamentos/193tecnologias-digitais-da-informacao-e-comunicacao-no-contexto-escolar-possibilidades

Brasil. (2012). Ministério da Educação. Secretaria de Educação Continuada, Alfabetização, Diversidade e Inclusão - SECADI. Educação do Campo: marcos normativos/Secretaria de Educação Continuada, Alfabetização, Diversidade e Inclusão - Brasília: SECADI.

Brasil. (2002). Resolução CNE/CEB 1/2002 - Institui Diretrizes Operacionais para a Educação Básica nas Escolas do Campo. MEC: Brasília - DF.

Brasil. (2008). Resolução CNE/CEB/2/2008 - Estabelece diretrizes complementares, normas e princípios para o desenvolvimento de políticas públicas de atendimento da Educação Básica do Campo. MEC: Brasília - DF

Caldart, R. S. (2003) A Escola do campo em movimento. Coletivo Nacional de Educação do MST e Instituto Técnico de Capacitação e Pesquisa da Reforma Agrária (ITERRA) Brasil. Currículo sem Fronteiras, 31, 60-81, Jan/Jun.

Candau, V. M. (2009). Educação intercultural na América Latina: Entre concepções, tensões e propostas. 7Letras

Candau, V. M. F. (2012). Diferenças culturais, interculturalidade e educação em direitos humanos. Educação \& Sociedade, 33(118), 235-250. https://doi.org/10.1590/s0101-73302012000100015.

Chagas, R.R; Pasush, J. (2016). Práticas pedagógicas na alfabetização de uma turma multisseriada no campo. Revista Even. Pedagóg. Número Regular: Experiências em Educação do Campo: perspectivas e práticas pedagógicas. Sinop, 7(3) (20. ed.), 1577-1603, ago./dez.

Costa, L. M. da. \& Batista, M. do S. X. (2021). O currículo na perspectiva da educação do campo: contraponto às políticas curriculares hegemônicas. Revista Espaço Do Currículo, 14(2), 1-15. https://doi.org/10.22478/ufpb.1983-1579.2021v14n2.58081

Fleuri, R. M., Costa, M. C. V. (2001). Travessia: questões e perspectivas da pesquisa em educação popular. Ijuí: Unijuí, 1. 124 https://repositorio.ufsc.br/xmlui/handle/123456789/18078

Pasuch, J. \& Chagas, R. R. (2016). Práticas pedagógicas na alfabetização de uma turma multiseriadas no campo. Revista Even. Sinop, 7(3) (20a ed.), 15771603, ago./dez. http://sinop.unemat.br/projetos/revista/index.php/eventos/index

Freire, P. (2004). Pedagogia da Autonomia: Saberes Necessários à Prática Educativa (2a ed.). Paz e Terra. 
Research, Society and Development, v. 11, n. 2, e16611225559, 2022

(CC BY 4.0) | ISSN 2525-3409 | DOI: http://dx.doi.org/10.33448/rsd-v11i2.25559

Instituto Nacional de Estudos e Pesquisas Educacionais Anísio Teixeira. (2019). Resumo Técnico: Censo da Educação Básica 2018 [recurso eletrônico]. Brasília: Instituto Nacional de Estudos e Pesquisas Educacionais Anísio Teixeira,66 p.: il.

Jesus, J. N. D. (2012). A pedagogia da alternância e o debate da educação no/do campo no estado de goiás. Revista Nera, (18), 7-20. https://doi.org/10.47946/rnera.v0i18.1334

Melo, A. D., \& Souza, S. C. (2013). Educação do campo e o programa escola ativa: elementos históricos, conceituais e pedagógicos. Holos, 2 , 178. https://doi.org/10.15628/holos.2013.1375

Nóvoa, A. (2013). Nada substitui um bom professor: propostas para uma revolução no campo de formação de professores. In: GATTI, Bernadete Angelina (Org.). Por uma política de formação de professores. São Paulo: Editora Unesp, 2013. p. 199-210.

Pires, L. S. (2020). Função do $1^{\circ}$ Grau em Narrativas de Produtores de leite bovino. Revista Latinoamericana de Etnomatemática Perspectivas Socioculturales de la Educación Matemática, 12(4). https://doi.org/10.22267/relatem.19124.35

Santos, G. dos S. dos, \& Moura, A. C. de O. S. de (2020b). Práticas pedagógicas que articulam a educação do campo com o ensino de ciências: uma revisão das publicações da revista brasileira de educação do campo. Revista Ciências \& Ideias. 11(2). https://doi.org/10.22407/2176-1477/2020.v11i2.1256

Santos, L. R., \& Chagas, P. C. D. M. (2011). Ensino de filosofia e EJA: contextualização histórica e desafios da contemporaneidade. Holos, 4, 182. https://doi.org/10.15628/holos.2011.643

Sena, R. E. F., \& Vilela, E. S. M. (2020). Educação do campo e currículo: território em disputa em uma escola de Campo Novo do Parecis-MT. Revista Espaço Do Currículo, 13(3), 517-530. https://doi.org/10.22478/ufpb.1983-1579.2020v13n3.52181

Silva, C. D., Andrade, K. D. S., \& Moreira, F. (2015). A retextualização no gênero Caderno da Realidade na Pedagogia da Alternância. Acta Scientiarum. Language and Culture, 37(4), 359. https://doi.org/10.4025/actascilangcult.v37i4.25050.

Sousa, A. P. F. de, Mello, R. M. A. V. de, \& Rodrigues, J. A. (2016). Práticas pedagógicas: interações, desafios e possibilidades no cotidiano de uma Escola Família Agrícola. Revista Brasileira de Educação do Campo, 1(2), 402-427. https://doi.org/10.20873/uft.2525-4863.2016v1n2p402

Zanlorenzi, M. A., \& Oliveira, A. M. (2017). Educação Matemática em territórios contestados: um currículo diferenciado para as ilhas do litoral do Paraná Mathematics Education in districts challenged: a differentiated curriculum for the islands of the coast of Paraná. Educação Matemática Pesquisa: Revista do Programa de Estudos Pós-Graduados em Educação Matemática, 19(3), 209. https://doi.org/10.23925/1983-3156.2017v19i3p209-229 